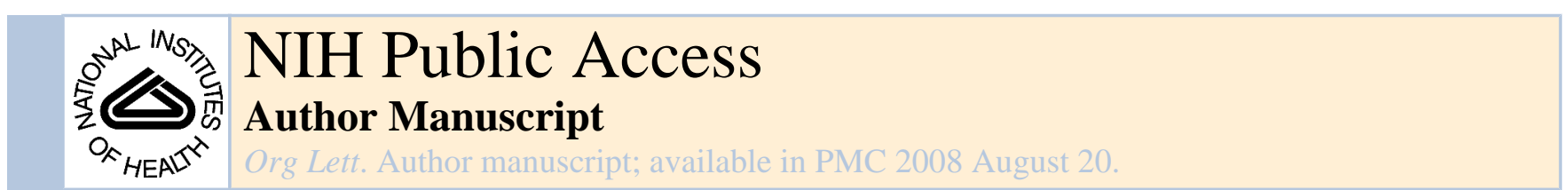

Published in final edited form as:

Org Lett. 2006 December 7; 8(25): 5725-5728.

\title{
Palladium Catalyzed Regiocontrolled a-Arylation of Trimethylsilyl Enol Ethers with Aryl Halides
}

\author{
Tetsuo Iwama and Viresh H. Rawal \\ Department of Chemistry, The University of Chicago 5735 South Ellis Avenue, Chicago, Illinois \\ 60637,vrawal@uchicago.edu
}

Abstract

$\mathrm{X}=\mathrm{Cl}, \mathrm{Br}, \mathrm{I}$<smiles>[X]c1ccccc1</smiles><smiles>COC1=CC(P)CCC1</smiles>

$\mathrm{R}^{\prime}=\mathrm{H}, \mathrm{Me}$

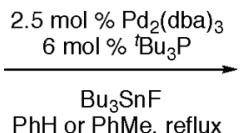

$\mathrm{PhH}$ or PhMe, reflux<smiles>O=C1CCCC(P)C1c1ccccc1</smiles>

Inter- and intramolecular arylations of trimethylsilyl enol ethers with aryl halides are accomplished regiospecifically in the presence of a palladium catalyst and tributyltin fluoride in refluxing benzene or toluene. The optimal catalyst system called for the use of $\operatorname{Pd}_{2}(\mathrm{dba})_{3}$ and tri-tert-butylphosphine in ca. 1:2 ratio. Aryl iodides, bromides and chlorides are all effective arylation partners in this reaction.

The direct introduction of an aryl unit at a nucleophilic carbon is a transformation of central importance to complex molecule synthesis. ${ }^{1}$ A synthetically useful subset of this class of reactions is the arylation of ketones at the $\alpha$-position. ${ }^{2}$ Such transformations are even more valuable in instances where the arylating agent is adorned with substitutents. For example, in connection with a route to Aspidosperma alkaloids, ${ }^{3}$ we developed a diaryl-iododonium reagent for the regiospecific ortho-nitrophenylation of an silyl enol ether, wherein subsequent reduction of the nitro group yielded indoles (e.g., eq 1). ${ }^{4}$ Our long-standing interest in transition metal catalyzed arylation and vinylation of phenolates (eq 2$)^{5}$ prompted us to examine procedures for the palladium catalyzed arylations of silyl enol ethers with aryl halides, and we report our results below. 6,7
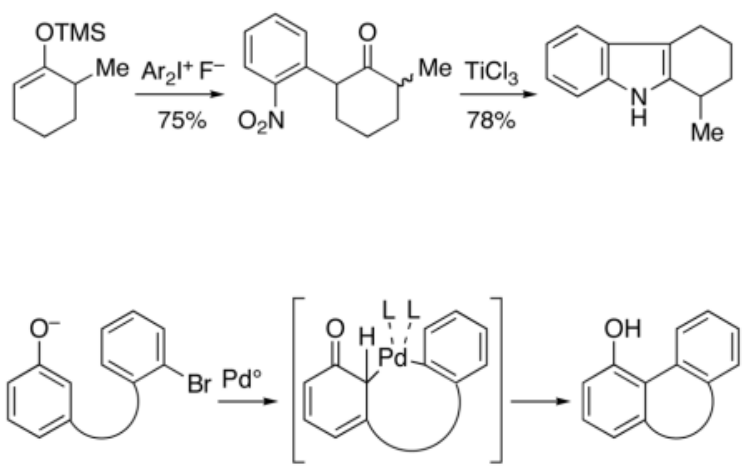
In pioneering work, Kuwajima and $\mathrm{Urabe}^{8}$ reported the palladium catalyzed $\alpha$-arylation of silyl enol ethers of ketones with aryl halides in the presence of $\mathrm{Bu}_{3} \mathrm{SnF}, 9,10,11$ The advantage of this method over the palladium catalyzed arylation of ketones under basic conditions is that it enables regiocontrol of the arylation rather than have it be controlled by the inherent kinetic or, more commonly, thermodynamic reactivity of the ketone. ${ }^{12,13,14,15}$ Furthermore, one can hope to exploit the rich chemistry of regioselective enolate formation and parlay it into a regioselective arylation procedure. ${ }^{16}$ Unfortunately, as originally reported, the scope of this reaction was rather limited, primarily to the arylation of the kinetic enol silyl ethers of methyl ketones. ${ }^{8}$ Even the arylation of cyclohexanone enol ether was reported to give $<15 \%$ yield of the $\alpha$-arylation product. We examined modern variations of this process and developed a general procedure for the regiospecific inter- and intramolecular arylation of various ketone enol silyl ethers. 6,7

In considering the results and probable mechanism of the Kuwajima-Urabe arylation, the problematic steps appeared to be either the transmetalation of the putative tin enolate to the arylpalladium enolate or its reductive elimination to the arylated ketone. Assuming the latter was the issue, the expectation was that this step could be accelerated through the use of the bulky ligand $t-\mathrm{Bu}_{3} \mathrm{P} .{ }^{17}$ Numerous reaction conditions were examined for the arylation of cyclohexanone trimethylsilyl enol ether (2) with $p$-iodoanisole (equation 1). ${ }^{18,19}$ Of the reaction parameters examined, the combination that afforded cleanest reaction involved the use of $2.5 \mathrm{~mol} \%$ of $\mathrm{Pd}_{2}(\mathrm{dba})_{3}, 6 \mathrm{~mol} \%$ of $t-\mathrm{Bu}_{3} \mathrm{P}$, and 1 equiv of $\mathrm{Bu}_{3} \mathrm{SnF}$ in refluxing benzene. However, the reaction was slow under these conditions and reached only $\sim 50 \%$ completion after $20 \mathrm{~h}$. On the other hand, it progressed well when the silyl enol ether and tin fluoride were used in excess ( 2 equiv each), and afforded arylated product 3a in $82 \%$ isolated yield (Table 1 , entry 1).

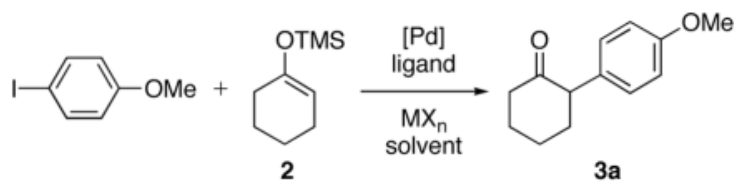

The standard conditions described above were utilized to perform the arylation of $\mathbf{2}$ with various aryl halides, and the results are summarized in Table $1.20,21$ The arylation of 2 with pbromoanisole under the same conditions afforded cyclohexanone 3a in 78\% yield (entry 2). Arylation product 3a was obtained in slightly lower yield when the bulky ligand 2-(di-tertbutylphosphino)biphenyl was used (entry 3). Even the corresponding aryl chloride gave the arylated product in good yield, provided the reaction was carried out at a slightly higher temperature, in refluxing toluene (entry 4). By contrast, the corresponding triflate was unreactive and was recovered cleanly (by ${ }^{1} \mathrm{H}$ NMR) after $18 \mathrm{~h}$. Other electron-rich aryl halides were also effective coupling partners (entries 6,11-14). The successful use of $o$-chlorotoluene, in particular, is noteworthy, since it is both electron rich and sterically encumbered. Aryl halides possessing an electron-withdrawing group at the para position gave the respective arylated products in good yields (entries 7-10). By comparison, o-nitro-substituted aryl halides $(\mathrm{Cl}, \mathrm{Br}$, I) were poor arylating agents, and only $o$-chloronitrobenzene gave any of the arylation product (entry 15). Some of the above arylations were also carried out successfully in toluene at $80^{\circ}$ $\mathrm{C}$ instead of refluxing benzene.

To explore the generality of the arylation protocol, additional TMS enol ethers were prepared and subjected to standard arylation protocol (Table 2). ${ }^{16}$ Entry 1 highlights an important feature of the silyl enol ether arylation method: arylations take place regiospecifically. Thus, 
arylation of enol ether 4 , prepared easily and regiospecifically by methylcuprate addition to 2 cyclohexenone, ${ }^{22}$ with $p$-iodoanisole gave arylated product 5 as a single regio- and stereoisomer in $72 \%$ yield. ${ }^{23}$ Evidently, the putative tin and palladium enolate intermediates do not equilibrate to the regioisomeric, less-hindered enolates. Norbornanone-derived enol ether 6 reacted slowly with $p$-iodoanisole to produce the expected arylation product (7) in 58\% yield together with recovered $p$-iodoanisole (entry 2). Also slow to react was the acyclic enol ether $8 .{ }^{8}$ This reaction was carried out in refluxing benzene using $p$-bromoanisole as the arylating agent, and examination of the reaction mixture by ${ }^{1} \mathrm{H}$ NMR after $9 \mathrm{~h}$ showed the presence of primarily unreacted $\mathbf{8}$. In refluxing toluene, however, this arylation proceeded well and afforded 9 in $70 \%$ yield (entry 3 ). When this reaction was carried out with $p$-iodoanisole, it proceeded in low yield and produced unindentified byproducts. A competition experiment (eq 4) showed that the aryl iodide is consumed faster than the bromide, consistent with the expected relative rates of oxidative addition of $\mathrm{Pd}^{0}$. These observations indicate that oxidative addition of $\mathrm{Pd}^{0}$ onto the aryl halide is not the rate determining step in the reaction and suggest that the Pd-intermediate formed from the aryl iodide is less competent, due to either poor reactivity or stability, than that from the aryl bromide at proceeding to the product.

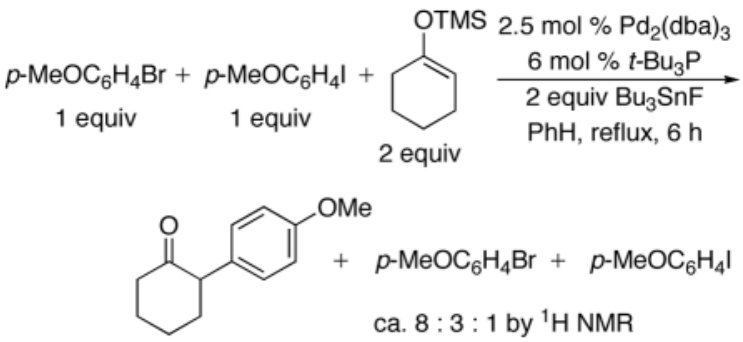

The synthetic utility of this method was further developed through the examination of substrates in which the arylation would take place intramolecularly (Table 3). ${ }^{14}$ Treatment of TMS enol ether 10 with 1 equiv of $\mathrm{Bu}_{3} \mathrm{SnF}, 5 \mathrm{~mol} \%$ of $\mathrm{Pd}_{2}(\mathrm{dba})_{3}$ and $12 \mathrm{~mol} \%$ of $t-\mathrm{Bu}_{3} \mathrm{P}$ in benzene furnished [3.3.1] bicyclic product 11 in $62 \%$ yield together with $12 \%$ of the uncyclized ketone, corresponding to the hydrolysis product of $\mathbf{1 1}$. The arylative cyclization of $\mathbf{1 2}$ required higher temperature (refluxing toluene) and gave $\mathbf{1 3}$ in $66 \%$ yield, accompanied by the uncyclized ketone (12\%). In both cases, lower loadings of $\mathrm{Pd}_{2}(\mathrm{dba})_{3}(2.5 \mathrm{~mol} \%)$ and $t-\mathrm{Bu}_{3} \mathrm{P}$ $(6 \mathrm{~mol} \%)$ resulted in slower reactions and increased amounts of the ketone arising from hydrolysis of the starting material. On the other hand, the reaction of 14 with $2.5 \mathrm{~mol} \%$ of $\mathrm{Pd}_{2}(\mathrm{dba})_{3}$ and $6 \mathrm{~mol} \%$ of $t-\mathrm{Bu}_{3} \mathrm{P}$ in refluxing benzene afforded arylation product 15 high yield (entry 3). All three of the entries are noteworthy in that they produce a [3.3.1]-bicyclic array. The final entry shows the construction of tetrahydrofluorenone $\mathbf{1 7}$ through the intramolecular arylation method. In this case the arylated product (17), assumed to be cis, was formed in $46 \%$ yield along with $24 \%$ of the recovered ketone.

A plausible mechanism for the Pd-catalyzed arylation of TMS enol ethers is shown in Scheme 1. The starting TMS enol ether is expected to react with $\mathrm{Bu}_{3} \mathrm{SnF}$ to generate tin enolate $\mathbf{A}$, which is under equilibrium with $\alpha$-stannyl ketone $\mathbf{B} .^{8,24}$ The reaction of the tin enolate with Ar-Pd-X would produce the transmetalation product, Pd-enolates $\mathbf{C} .{ }^{9-11}$ Reductive elimination of $\mathbf{C}$ to give a $\mathrm{C}-\mathrm{C}$ bond then gives the arylation product and regenerates $\mathrm{Pd}^{0}$.

In summary, Pd-catalyzed arylation of TMS enol ethers was achieved in both inter- and intramolecular manner by use of $\mathrm{Pd}_{2}(\mathrm{dba})_{3}$ and $t-\mathrm{Bu}_{3} \mathrm{P}$ in the presence of $\mathrm{Bu}_{3} \mathrm{SnF}$. Electronpoor and electron-rich aryl halides, including iodides, bromides and chlorides, participated in 
the present arylation. Significantly, the arylations proceeded with complete regiospecificity and with a range of substrates.

\section{Supplementary Material}

Refer to Web version on PubMed Central for supplementary material.

\section{Acknowledgements}

We thank the National Institutes of Health for financial suport of this work. We also thank Merck \& Co. for additional support.

\section{References}

1. Abramovitch RA, Barton DHR, Finet JP. Tetrahedron 1988;44:3039-3071.

2. Selected examples of $\alpha$-arylation of ketones that do not involve Pd catalysis: (a) Semmelhack MF, Chong BP, Stauffer RD, Rogerson TD, Chong A, Jones LD. J Am Chem Soc 1975;97:2507-2516. [PubMed: 1133420] (b) Sakakura T, Hara M, Tanaka M. J Chem Soc, Chem Commun 1985:15451546. (c) Rathke MW, Vogiazoglou D. J Org Chem 1987;52:3697-3698. (d) Negishi EI, Akiyoshi K. Chem Lett 1987:1007-1010. (e) Finet JP. Chem Rev 1989;89:1487-1501. (f) Chen K, Koser GFJ. Org Chem 1991;56:5764-5767. (g) Morgan J, Pinhey JT, Rowe BA. J Chem Soc Perkin Trans 1 1997:1005-1008. (h) Mino T, Matsuda T, Maruhashi K, Yamashita M. Organometallics 1997;16:3241-3242. (i) Ryan JH, Stang PJ. Tetrahedron Lett 1997;38:5061-5064. Oxidative arylation of ketone enolate: (j) Bhowmik DR, Venkateswaran RV. Tetrahedron Lett 1999;40:7431-7433. (k) Deng H, Konopelski JP. Org Lett 2001;3:3001-3004. [PubMed: 11554828] (1) Ooi T, Maruoka K. J Am Chem Soc 2003;125:10494-10495. [PubMed: 12940712] (m) Koech PK, Krische MJ. J Am Chem Soc 2004;126:5350-5351. [PubMed: 15113193] For a comprehensive listing of methods for $\alpha$ arylation of ketones, see ref. 13d.

3. (a) Kozmin SA, Rawal VH. J Am Chem Soc 1998;120:13523-13524. (b) Kozmin SA, Iwama T, Huang Y, Rawal VH. J Am Chem Soc 2002;124:4628-4641. [PubMed: 11971711]

4. (a) Iwama T, Birman VB, Kozmin SA, Rawal VH. Org Lett 1999;1:673-676. [PubMed: 10823199] The direct o-nitroarylation of enolates with aryliodonium salts has also been reported: (b)

RawalVHTakenakaNIwamaTAbstracts of Papers, 222nd ACS National MeetingChicago, IL, United StatesAugust 26-30, 2001 ORGN-007 (For a detailed abstract, see Chemical Abstracts: AN 2001:640370). For a full discussion of this work, see: TakenakaNPh D DissertationUniversity of ChicagoChicago, IL2002 For a related report, see: (c) Aggarwal VK, Olofsson B. Angew Chem Int Ed 2005;44:5516-5519.

5. (a) Hennings DD, Iwasa S, Rawal VH. J Org Chem 1997;62:2-3. [PubMed: 11671356] (b) Hennings DD, Iwasa S, Rawal VH. Tetrahedron Lett 1997;38:6379-6382. (c) Hennings DD, Iwama T, Rawal VH. Org Lett 1999;1:1205-1208.For application to complex molecule synthesis: (d) MacKay JA, Bishop RL, Rawal VH. Org Lett 2005;7:3421-3424. [PubMed: 16048307]

6. The contents of this paper were presented at the $222^{\text {nd }}$ ACS National meeting: Rawal, V. H.; Iwama, T. Abstracts of Papers, $222^{\text {nd }}$ ACS National Meeting, Chicago, IL, United States, August 26-30, 2001, ORGN-606 (For a detailed abstract, see Chemical Abstracts: AN 2001:640969). This work was also presented at the ACS $33^{\text {rd }}$ Great Lakes/Central Regional Meeting, Grand Rapids, MI, June 1113,2001 .

7. A recent publication by Verkade, Hartwig and coworkers, describing the use of similar conditions, that appeared on the web prompts us to present fully our previously reported work (Ref. 6) in this area. See: Su W, Raders S, Verkade JG, Liao X, Hartwig JF. Angew Chem Int Ed "Early View". 17 July; 2006

8. Kuwajima I, Urabe H. J Am Chem Soc 1982;104:6831-6833.

9. Other early examples of Pd-catalyzed $\alpha$-arylation that go through stannyl enolates: (a) Kosugi M, Sizuki M, Hagiwara I, Goto K, Saitho K, Migita T. Chem Lett 1982:939-940. (b) Kosugi M, Hagiwara I, Sumiya T, Migita T. J Chem Soc, Chem Commun 1983:344-345. (c) Kosugi M, Hagiwara I, Sumiya T, Migita T. Bull Chem Soc Jpn 1984;57:242-246. (d) Sakakura T, Kara M, Tanaka M. J Chem Soc, 
Perkin Trans 1 1994:283-288. Antimony enolate: (e) Kang SK, Ryu HC, Hong YT. J Chem Soc, Perkin Trans 1 2000:3350-3351.

10. Pd-catalyzed arylations of silyl ketene acetals: (a) Carfagna C, Musco A, Sallese G, Santi R, Fiorani T. J Org Chem 1991;56:261-263. (b) Galarini R, Musco A, Pontellini R, Santi R. J Mol Catal 1992;72:L11-L13. (c) Sakamoto T, Kondo Y, Masumoto K, Yamanaka H. Heterocycles 1993;36:2509-2512. (d) Sakamoto T, Kondo Y, Masumoto K, Yamanaka H. J Chem Soc, Perkin Trans 1 1994:235-236. (e) Agnelli F, Sulikowski GA. Tetrahedon Lett 1998;39:8807-8810. (f) Lee S, Lee WM, Sulikowski GA. J Org Chem 1999;64:4224-4225. (g) Liu X, Hartwig JF. J Am Chem Soc 2004;126:5182-5192. [PubMed: 15099101]

11. For recent developments on Pd-catalyzed arylation of silyl enol ethers or related species, see: (a) Hama T, Culkin DA, Hartwig JF. J Am Chem Soc 2006;128:4976-4985. [PubMed: 16608331] and references cited therein (b) Chae J, Yun J, Buchwald SL. Org Lett 2004;6:4809-4812. [PubMed: 15606072] and references cited therein

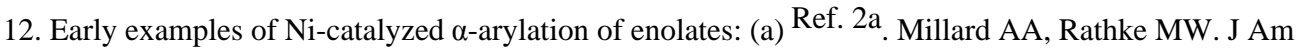
Chem Soc 1977;99:4833-4835.

13. For the Pd-catalyzed intermolecular arylation of carbonyl compounds, see: (a) Palucki M, Buchwald SL. J Am Chem Soc 1997;119:11108-11109. (b) Hamann BC, Hartwig JF. J Am Chem Soc 1997;119:12382-12383. (c) Kawatsura M, Hartwig JF. J Am Chem Soc 1999;121:1473-1478. (d) Fox JM, Huang X, Chieffi A, Buchwald SL. J Am Chem Soc 2000;122:1360-1370. (e) Ehrentraut A, Zapf A, Beller M. Adv Synth Catal 2002;344:209-217. (f) Marion N, Ecarnot EC, Navarro O, Amoroso D, Bell A, Nolan SP. J Org Chem 2006;71:3816-3821. [PubMed: 16674054] and references cited therein. Review: (g) Culkin DA, Hartwig JF. Ace Chem Res 2003;36:234-245.

14. Intramolecular $\alpha$-arylation of enolates: (a) Muratake H, Natsume M, Nakai H. Tetrahedron 2004;60:11783-11803. and references cited therein (b) Shaughnessy KH, Hamann BC, Hartwig JF. J Org Chem 1998;63:6546-6553. (c) Sole D, Vallverdu L, Solans X, Font-Bardia M, Bonjoch J. J Am Chem Soc 2003;125:1587-1594. [PubMed: 12568619] (d) Honda T, Sakamaki Y. Tetrahedron Lett 2005;46:6823-6825.(e) Ref. 5d.

15. For early reports on Pd-catalyzed alkenylation of enolates, see: (a) Piers E, Marais PCJ. Org Chem 1990;55:3454-3455. (b) Piers E, Renaud JJ. Org Chem 1993;58:11-13.See also (c) and references cited therein Yu JM, Wang T, Liu XX, Deschamps J, Flippen-Anderson J, Liao XB, Cook JMJ. Org Chem 2003;68:7565-7581. (d) Sole D, Urbaneja X, Bonjoch J. Adv Synth Catal 2004;346:16461650.and references cited therein (e) Chieffi A, Kamikawa K, Ahman J, Fox JM, Buchwald SL. Org Lett 2001;3:1897-1900. [PubMed: 11405739]

16. (a) Heathcock CH. Modern Synthetic Methods 1992;6:1-102.Kobayashi, S.; Manabe, K.; Ishitani, H.; Matsuo, J-I. Science of Synthesis. Bellus, D., et al., editors. 9. Georg Thieme; Stuttgart: 2002. p. 317-369.

17. (a) Nishiyama M, Yamamoto T, Koie Y. Tetrahedron Lett 1998;39:617-620. (b) Nishiyama M, Yamamoto T, Koie Y. Tetrahedron Lett 1998;39:2367-2370. (c) Littke AF, Fu GC. Angew Chem Int Ed 1998;37:3387-3388. (d) Shaughnessy KH, Kim P, Hartwig JFJ. Am Chem Soc 1999;121:2123-2132.See also Ref. 13g

18. This combination was selected as it was expected to be a challenging arylation, since not only is the phenylation cyclohexanone reported to be low yielding (Ref. 8), but the oxidative addition to the electron-rich $o$-bromoanisole was expected to be slow.

19. An extensive screening of reaction conditions was carried out. Pd sources examined: $\mathrm{PdCl}_{2}\left(\mathrm{Ph}_{3} \mathrm{P}\right)_{2}, \mathrm{PdCl}_{2}\left(o-\mathrm{Tol}_{3} \mathrm{P}\right)_{2}, \mathrm{PdCl}_{2}, \mathrm{Pd}_{2}(\mathrm{dba})_{3}, \mathrm{Pd}(\mathrm{OAc})_{2}$, or $\mathrm{PtCl}_{2}(\mathrm{PhCN})_{2}$; Phosphine ligands: BINAP, Tol-BINAP, $t$-Bu 3 P, $(t \text {-BuCH})_{3} \mathrm{P}, 2$-(di-tert-butylphosphino)biphenyl, ${ }^{\mathrm{C}} \mathrm{Hex}_{3} \mathrm{P}, \mathrm{Ph}_{3} \mathrm{P},(o$ Tol) $)_{3} \mathrm{As}, \mathrm{Ph}_{3} \mathrm{As}$, and $i$-PrO) ${ }_{3} \mathrm{P}$; Fluoride sources: $\mathrm{Bu}_{3} \mathrm{SnF}, \mathrm{LiF}, \mathrm{NaF}, \mathrm{CsF}, \mathrm{CuF}_{2}, \mathrm{ZnF}_{2}, \mathrm{ZrF}_{4}, \mathrm{KF}$, $\mathrm{ZnCl}_{2}, \mathrm{SnCl}_{4}$, or $\mathrm{Me}_{4} \mathrm{NF}$; Solvents: benzene, toluene, DMF, or THF; Additives: $\mathrm{LiCl}, \mathrm{NaOAc}$ and $t$-BuOK.

20. General procedure for Pd-catalyzed arylation: A mixture containing TMS enol ether (1 mmol), aryl halide $(0.5 \mathrm{mmol}), 2.5 \mathrm{~mol} \%$ of $\mathrm{Pd}_{2}(\mathrm{dba})_{3}(11.4 \mathrm{mg})$, and $\mathrm{Bu}_{3} \mathrm{SnF}(309 \mathrm{mg}, 1 \mathrm{mmol})$ under a nitrogen atmosphere was treated with a solution of $t \mathrm{Bu}_{3} \mathrm{P}(7.5 \mu \mathrm{L})$ in benzene $(2 \mathrm{~mL})$ at room temperature. The resultant mixture was heated to reflux. After cooling to room temperature, the reaction mixture was diluted with ether $(20 \mathrm{~mL})$ (when the precipitate of tin residue was formed, it was removed by decantation with ether), washed with $1 \mathrm{~N}$ aqueous $\mathrm{NaOH}$ twice $(5 \mathrm{~mL}$ each) followed by brine $(5 \mathrm{~mL}$ 
$\times 2$ ), dried $\left(\mathrm{MgSO}_{4}\right)$, and concentrated. The residue was purified by flash column chromatography on silica gel.

21. The success of this reaction is dependent on the quality of $t-\mathrm{Bu}_{3} \mathrm{P}$. Irreproducible results were obtained with one, newly-purchased bottle of $t-\mathrm{Bu}_{3} \mathrm{P}$.

22. (a) Binkley ES, Heathcock CHJ. Org Chem 1975;40:2156-2160. (b) Dieter RK, Dieter JW. J Chem Soc, Chem Commun 1983:1378-1380.

23. The product arising from the regioisomeric enolate was not detected in the ${ }^{1} \mathrm{H}$ NMR of the crude reaction mixture. Product 5 was assigned the trans stereochemistry based on the coupling constant of the 2,3-vicinal protons $(J=11.5 \mathrm{~Hz})$.

24. Shibata I, Baba A. Org Prep Proced Int 1994;26:85-100. 


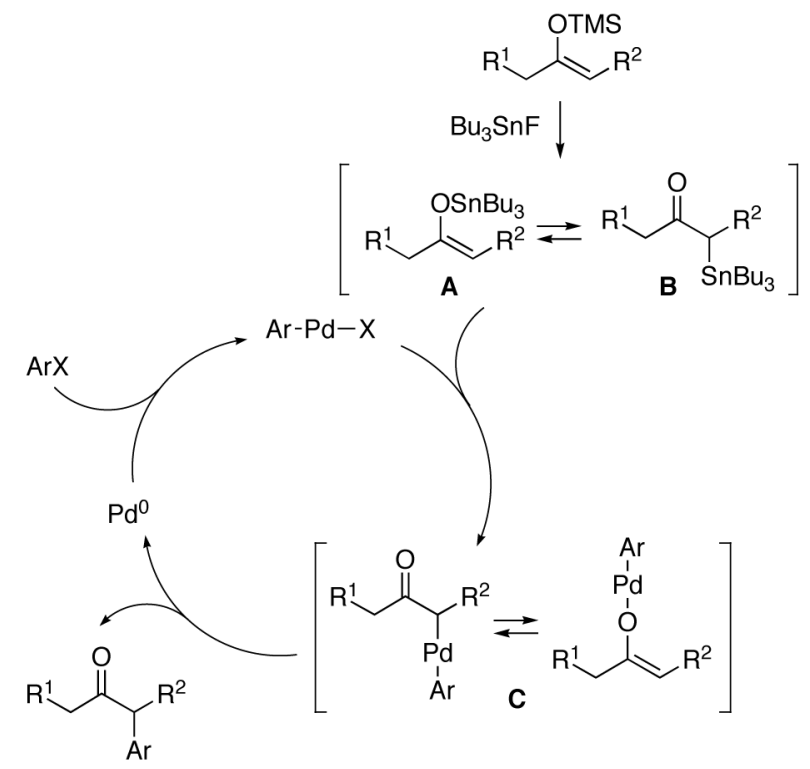

Scheme 1. 


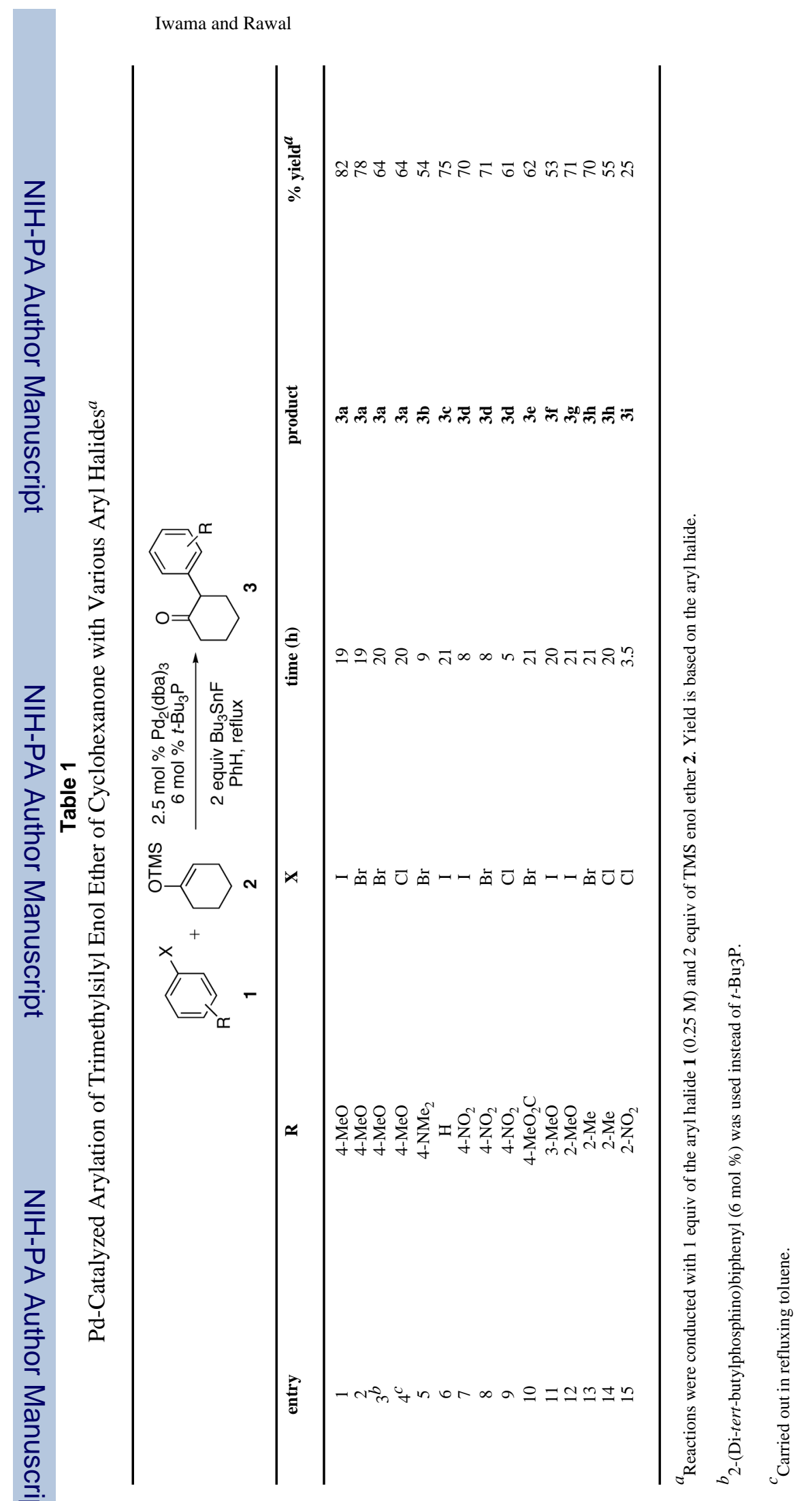

Org Lett. Author manuscript; available in PMC 2008 August 20. 


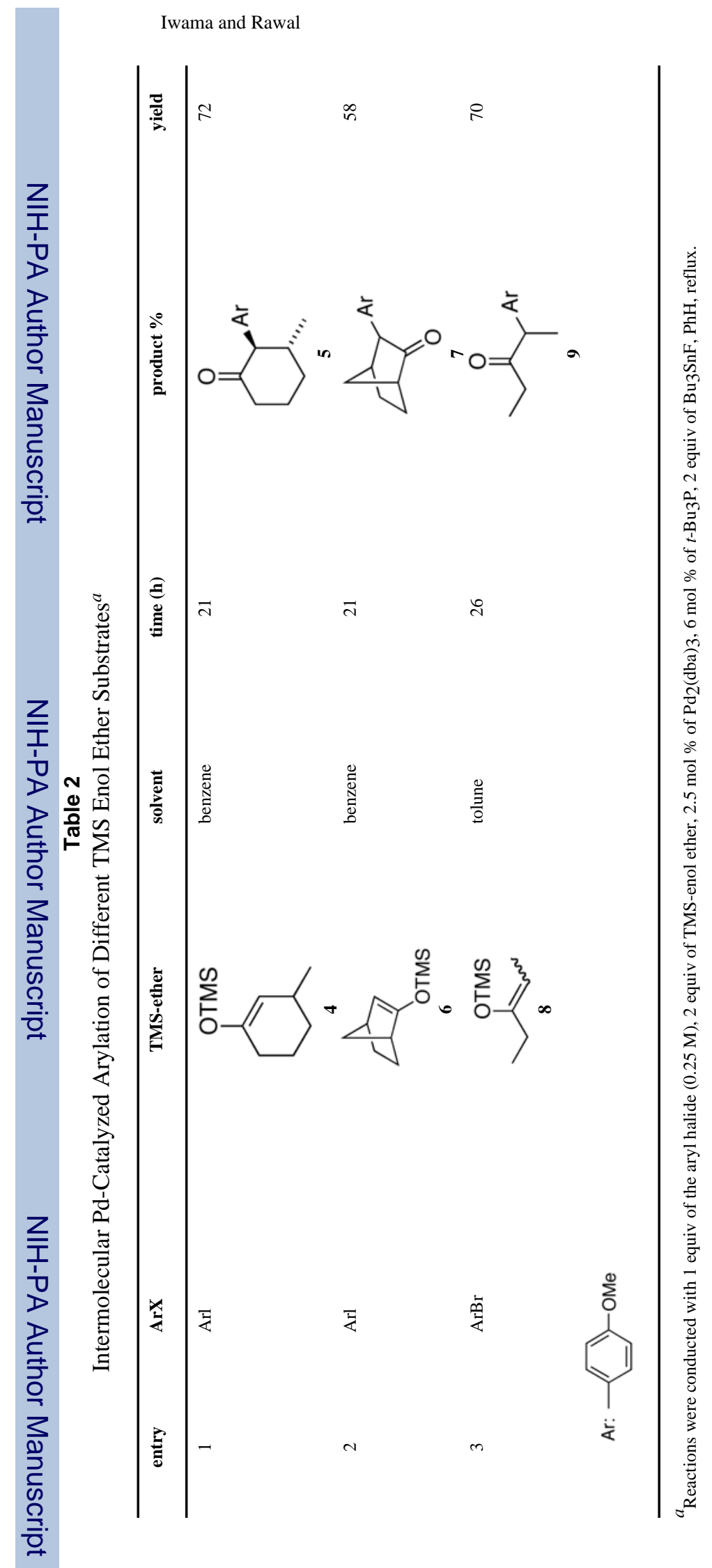

Page 9

Org Lett. Author manuscript; available in PMC 2008 August 20. 


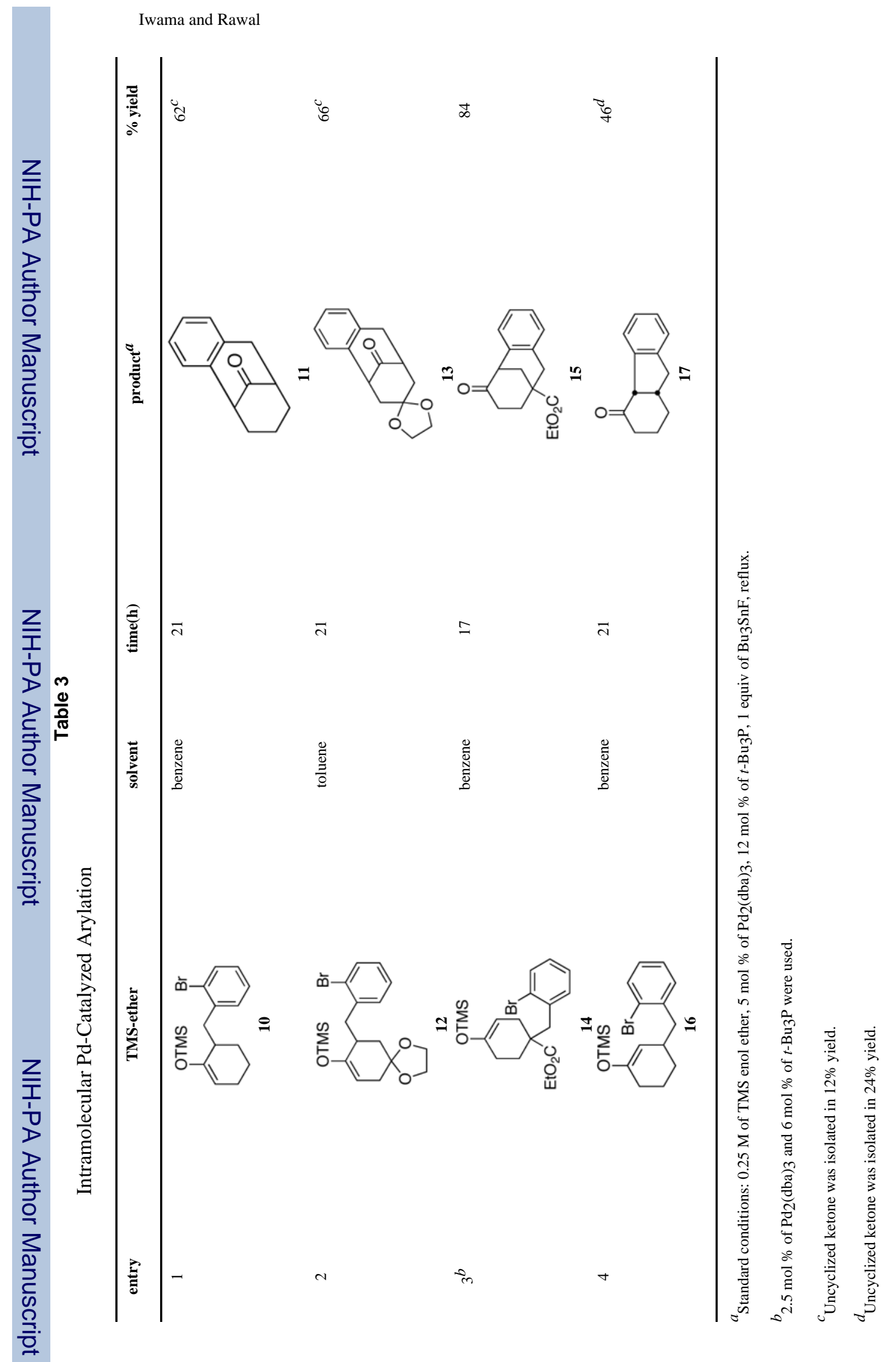

Org Lett. Author manuscript; available in PMC 2008 August 20. 